\title{
G009 CHARACTERIZATION OF THE MN SITES IN MANGANESE REDOX PROTEINS: MN CATALASE AND THE PHOTOSYNTHETIC OXYGEN EVOLVING COMPLEX.
}

P.J. Riggs a, R. Meib, G.S. Waldo ${ }^{a}$, C.F. Yocuma, ${ }^{a}, L, E$, Penner-Hahna, aDepartment of Chemistry, and bDepartment of Biology. University of Michigan, Ann Arbor, MI 48109-1055. USA.

Manganese redox enzymes play crucial roles in a variety of biological systems. These include the photosynthetic oxidation of water to dioxygen, the disproportionation of hydrogen peroxide, the disproportionation of superoxide, and ribonucleotide reduction. The $\mathrm{Mn}$ sites in two of these systems, the photosynthetic oxygen evolving complex (OEC) and the $\mathrm{Mn}$ catalase from $L$. plantarum have been characterized using a combination of $x$ ray absorption spectroscopy, epr spectroscopy, and activity measurements.

A characteristic feature of the OEC is the presence of a $2.7 \AA \mathrm{Mn}-\mathrm{Mn}$ interaction observed by EXAFS [1]. This feature reflects the presence of ca. 2-3 short $\mathrm{Mn}-\mathrm{Mn}$ interactions in the multinuclear $\mathrm{Mn}$ cluster. We have found recently that in the presence of high concentrations of $\mathrm{Ca}(\mathrm{II})$ the $\mathrm{OEC}$ can be reduced with no loss of activity. The XANES spectrum for the reduced OEC shows that ca. $50 \%$ of the $\mathrm{Mn}$ has been reduced to $\mathrm{Mn}(\mathrm{II})$ (consistent with observations from epr). However, the EXAFS spectra show that at least one of the short $(2.7 \AA) \mathrm{Mn}-\mathrm{Mn}$ interactions remains intact in the reduced OEC. The implications of this finding as regards the OEC structure will be discussed.

Three Mn containing catalases have recently been characterized. The Mn catalase from $L$, plantarum has been found to contain a dinuclear $\mathrm{Mn}$ site, and the as isolated enzyme exhibits a 16-line epr signal similar to that observed for the $S_{2}$ state of the OEC [2]. On the basis of the correlation between activity and epr intensity, and the correlation between activity and oxidation state (as determined by XANES) we find that Mn catalase utilizes a $\mathrm{Mn}(\mathrm{II} / \mathrm{Mn}(\mathrm{II}) \leftrightarrow$ $\mathrm{Mn}$ (III)/Mn(III) catalytic cycle. The species giving rise to the 16 -line epr signal is shown unambiguously to be a $\mathrm{Mn}(\mathrm{III}) / \mathrm{Mn}(\mathrm{IV})$ mixed valence dimer. The Mn(III)/Mn(IV) form is catalytically inactive as a result of its slow rate of reduction (in contrast with the very rapid reduction observed for the $\mathrm{Mn}(\mathrm{III}) / \mathrm{Mn}$ (III) derivative). Structurally, the inactive Mn catalase is very similar to the active OEC, as judged from the similarity of their EXAFS spectra. The differences in the site structures for the OEC and the catalase will be discussed in the context of the likely mechanisms for the two enzymes.

Supported in part by the NIH (GM-38047 to JEPH) the NSF (DCB-85-15932 to CFY) and the USDA (CRGO-88-37130-3546 to CFY)

1. A.E. McDermott et al., Biochem. 27, 2041 (1988) and refs. therein; J.E. Penner-Hahn, et al., J. Am. Chem. Soc., 112, 2549 (1990).

2. W.F. Beyer, Jr., I. Fridovich, Biochem., 24, 6460 (1985); R.M. Fronko, J.E. Penner-Hahn, C.J. Bender, I. Am. Chem. Soc., 110. 7554 (1988). 